\title{
Moderate drought did not affect the effectiveness of ethylenediurea (EDU) in protecting Populus cathayana from ambient ozone
}

\author{
Yue Xin a,b,c,d, Xiangyang Yuan ${ }^{\mathrm{a}, \mathrm{b}}$, Bo Shang ${ }^{\mathrm{a}, \mathrm{b}}$, William J. Manning ${ }^{\mathrm{e}}$, Aizhen Yang ${ }^{\mathrm{c}}$, \\ Younian Wang ${ }^{\mathrm{c}, *}$, Zhaozhong Feng ${ }^{\mathrm{a}, \mathrm{b}, \mathrm{c}, * *}$
}

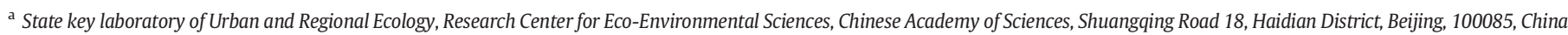

b University of Chinese Academy of Sciences, Shijingshan District, Beijing 100049, China

c Key Laboratory of Urban Agriculture (North) of Ministry of Agriculture P. R. China, Beijing University of Agriculture, Beijing 102206, China

d Institute of Geographic Sciences and Natural Resources Research, Chinese Academy of Sciences, 11A, Datun Road, Chaoyang District, Beijing, 100101, China

e Stockbridge School of Agriculture, University of Massachusetts, Amherst, MA 01003-9320, USA

\section{H I G H L I G H T}

- Protection of EDU on plants against ozone $\left(\mathrm{O}_{3}\right)$ is not known when water is limited.

- Effects of EDU on Populus cathayana were tested at two soil water contents.

- EDU efficiently protects $P$. cathayana from $\mathrm{O}_{3}$ when soil water is moderate drought.

- $P$. cathayana could be used as a biomarker in $\mathrm{O}_{3}$ risk assessment on plant health.
G R A P H I C A L A B S T R A C T

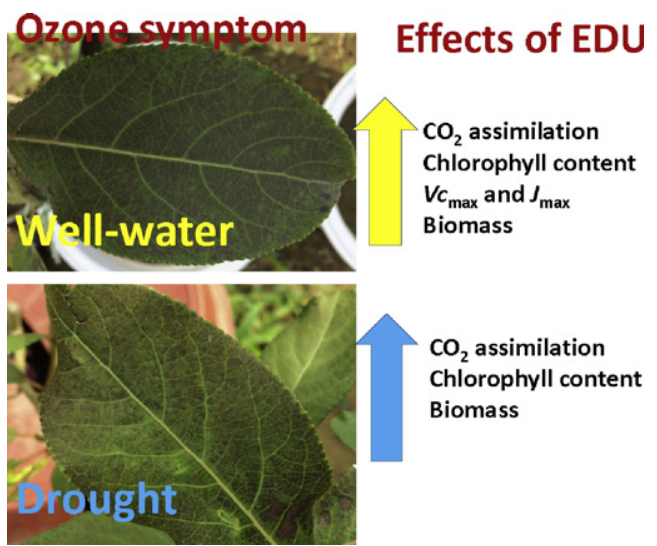

\section{A R T I C L E I N F O}

\section{Article history:}

Received 23 March 2016

Received in revised form 10 June 2016

Accepted 30 June 2016

Available online 14 July 2016

\section{Keywords:}

Ambient ozone

Drought

Ethylenediurea

Photosynthesis

Poplar

\begin{abstract}
A B S T R A C T
A field study was conducted to evaluate the effects of ambient ozone $\left(\mathrm{O}_{3}\right)$ on an $\mathrm{O}_{3}$-sensitive poplar (Populus cathayana) by using ethylenediurea (EDU) as a chemical protectant under two soil water treatments (wellwatered (WW) and moderate drought (MD, 50-60\% of WW in volumetric soil water content). EDU was applied as foliar spray at $0,300,450$, and $600 \mathrm{ppm}$. Photosynthetic parameters, pigment contents, leaf nitrogen, antioxidant capacity, growth, and biomass were measured. The $8 \mathrm{~h}$ (9:00-17:00) average ambient $\mathrm{O}_{3}$ concentration was $71.7 \mathrm{ppb}$, and AOT40 was $29.2 \mathrm{ppm}$ h during the experimental period (9 June to 21 September), which was high enough to cause plant injury. MD had significantly negative effects on $P$. cathayana, as indicated by reduced photosynthesis, growth, and biomass, and higher MDA contents. On the other hand, EDU significantly increased photosynthesis rate, chlorophyll $a$ fluorescence, $V_{\text {cmax }}$ and $J_{\max }$, photosynthetic pigments, total antioxidant capacity, tree growth and biomass accumulation, and reduced lipid peroxidation, but there was no significant interaction between EDU and drought for most parameters, indicating that EDU can efficiently protect
\end{abstract}

\footnotetext{
* Corresponding author.

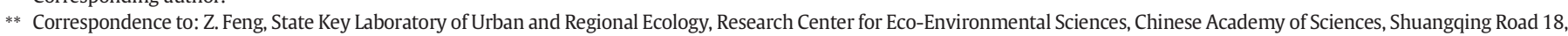
Haidian District, Beijing, 100085, China.

E-mail addresses: wyn1951@126.com (Y. Wang), fzz@rcees.ac.cn (Z. Feng).
} 
Populus cathayana against ambient $\mathrm{O}_{3}$ and the protection was not affected by soil water contents when soil water reached moderate drought level. Among all doses, EDU at $450 \mathrm{ppm}$ provided maximum protection. Comparison of EDU-treated and non-treated $P$. cathayana could be used as a biomarker system in risk assessment of the effects of ambient $\mathrm{O}_{3}$ on forest health.

(C) 2016 Published by Elsevier B.V.

\section{Introduction}

Tropospheric ozone $\left(\mathrm{O}_{3}\right)$ is an important photochemical secondary pollutant and a significant greenhouse gas (The Royal Society, 2008). $\mathrm{O}_{3}$ concentrations are increasing in East Asia and will continue to rise if current levels of anthropogenic activities are continued and more nitrogen oxides and volatile organic compounds are produced (Yamaji et al., 2008). In China, $\mathrm{O}_{3}$ concentration is rising at a higher rate than in other countries because $\mathrm{O}_{3}$ precursors (mainly $\mathrm{NO}_{2}$ ) have steadily increased at annual growth rate of $5 \%$ caused by its fast industrialization and urbanization (Feng et al., 2015). At Changping site, downwind of Beijing city, the AOT40 (accumulated hourly $\mathrm{O}_{3}$ concentration over a threshold of $40 \mathrm{ppb}$ during daytime) from June to August was $29 \mathrm{ppm}$ h in 2014 (Yuan et al., 2015). More than 28 species and cultivars in the open field showed the typical $\mathrm{O}_{3}$ symptoms around Beijing (Feng et al., 2014). Elevated $\mathrm{O}_{3}$ can negatively affect trees by inducing visible foliar injury and premature senescence and by decreasing the contents of photosynthetic pigments, photosynthesis rate, and biomass accumulation (Wittig et al., 2009; Hoshika et al., 2013; Carriero et al., 2015).

Ethylenediurea(N-[2-(2-oxo-1-imidazolidinyl)ethyl]- $\mathrm{N}$-phenyl urea), abbreviated as EDU, has been shown to be specific in protecting plants against $\mathrm{O}_{3}$ injury (Carnahan et al., 1978; Manning et al., 2003, 2011; Feng et al., 2010). EDU can reduce $\mathrm{O}_{3}$ injury, inhibit premature senescence, and maintain photosynthetic pigments in plants (Feng et al., 2010; Manning et al., 2011). Use of EDU as an alternative approach to evaluate the effects of $\mathrm{O}_{3}$ is an inexpensive and convenient method in ambient environment (Manning et al., 2011). So far, EDU has been used extensively to assess $\mathrm{O}_{3}$ impacts on crops, grasses, and trees in experiments where soil moisture was not limiting (Feng et al., 2010; Agathokleous et al., 2015).

Besides $\mathrm{O}_{3}$, plants are often subjected to drought in North China during summer. Recent evidence indicates that drought is one of the most costly natural hazards in North China due to the increasing water scarcity (Liu et al., 2015). Numerous studies showed that drought has many negative effects on plant growth, photosynthesis, biomass accumulation, and ecosystem carbon cycling (Liu et al., 2011; Zhou et al., 2013, 2015). Moreover, drought in summer often coincides with high $\mathrm{O}_{3}$ concentrations (Reiner et al., 1996).

From existing studies, possible interactions between $\mathrm{O}_{3}$ and drought have been determined to be antagonistic, additive, or synergistic (Pearson and Mansfield, 1994; Wieser and Havranek, 1995; Pääkkönen et al., 1998; Pollastrini et al., 2014; Tingey and Hogsett, 1985). Drought usually induces the closure of stomata, thus reducing the stomatal $\mathrm{O}_{3}$ flux into the apoplast, whereas EDU is retained in the apoplast only (Pasqualini et al., 2016). Therefore, it is important to investigate if EDU protects plants from $\mathrm{O}_{3}$ under drought. Poplars are important trees widely grown in most parts of China for timber purposes. It has been shown that most hybrid poplar species are sensitive to $\mathrm{O}_{3}$ with respect to visible leaf injury (Ryan et al., 2009; Hoshika et al., 2013), damaged photosystems ( $\mathrm{CO}_{2}$ assimilation and chlorophyll fluorescence) (Novak et al., 2005), and reduced growth (Bortier et al., 2000; Hoshika et al., 2013). As the representative deciduous tree species in Northern China, Populus trees are facing the risk of $\mathrm{O}_{3}$ damage due to high ground-level $\mathrm{O}_{3}$ pollution in China (Hu et al., 2015; Yuan et al., 2015).

In this study, Populus cathayana was selected because it is a native species distributed in the North China (Weisgerber and Han, 2000) and has been confirmed to be sensitive to $\mathrm{O}_{3}$ with typical $\mathrm{O}_{3}$ symptoms and significantly lower photosynthesis and biomass at AOT40 of 20 ppm.h in previous studies (Gao F. unpublished results). We propose that EDU protects the $P$. cathayana from ambient $\mathrm{O}_{3}$ at well-watered condition, but does not protect under drought stress due to reduced stomatal $\mathrm{O}_{3}$ flux. Therefore, the objectives of our study were to determine (1) if EDU could protect $P$. cathayana from the cumulative negative effects of ambient $\mathrm{O}_{3}$ in Beijing on biomass accumulation and ecophysiology, and (2) whether the protection of EDU was altered by moderate soil drought.

\section{Materials and methods}

\subsection{Experimental site}

The experiment was conducted under ambient conditions in Changping $\left(40^{\circ} 19^{\prime} \mathrm{N}, 116^{\circ} 13^{\prime} \mathrm{E}\right)$ in 2015 , northwest of Beijing in a warm temperate and semi-humid continental climate. The annual mean temperature in Changping is $11.8^{\circ} \mathrm{C}$ and the total annual precipitation is $550 \mathrm{~mm}$.

\subsection{Experimental design}

Cuttings of $P$. cathayana were provided by the Chinese Academy of Forestry Sciences and were cultivated in a small pot $(1.35 \mathrm{~L})$ filled with vermiculite and matrix (1:1) in a greenhouse of Research Center for Eco-Environmental Sciences, Chinese Academy of Sciences. Rooted cuttings were transplanted into $20 \mathrm{~L}$ circular plastic pots, filled with local sandy loam soil on June 9,2015 . The soil was excavated from farmland at $0-10 \mathrm{~cm}$ depth, sifted, and then mixed for the homogeneity. Pots were arranged in five rows, with 8 plants in each row. The space among pots were about $50 \mathrm{~cm}$. Plants with similar height and stem diameter were selected for this study and pre-adapted to the ambient conditions. All plants were manually irrigated up to maximum soil field capacity (36.8\%, volume content of soil) with tap water at 1-2 days interval to avoid drought before the drought treatment.

EDU was applied as sprays to leaves and stems of $P$. cathayana at 0 ppm (control E0), 300 ppm (E300), 450 ppm (E450), and 600 ppm (E600). Before treatments, the average height and stem diameter of the plants were $34.8 \mathrm{~cm}$ and $4.2 \mathrm{~mm}$, respectively, without significant difference among treatments $(P=0.95)$. The control was sprayed with water. EDU solutions were freshly prepared each time, dissolving $100 \%$ EDU in warm water (Manning et al., 2011). EDU application started at 19 days after planting (DAP) in pots, when the number of leaves is more than 10 , and then applied as a foliar spray five times at biweekly intervals until final harvest, considering the new leaves formation and EDU degradation with time (Manning et al., 2011). Before EDU application, no $\mathrm{O}_{3}$ symptoms were found on all plant leaves.

All plants were experienced two different water regimes by means of manual irrigation: well-watered (WW) and moderate drought (MD) plants. WW treatment was provided sufficient water up to soil field capacity during the entire experiment. For MD treatment, plants received $50-60 \%$ of soil water contents relative to WW throughout the experiment. During the experiment, the soil water content was monitored by means of Hydro Sense portable soil moisture meter (HS II, USA). The average soil water contents of WW and MD during experiment were $29 \%$ and $18 \%$. The pots of both WW and MD plants were protected from rain with a plastic cover during rainy time.

There were eight combinations of EDU and water treatments, i.e. WE0, WE300, WE450, WE600, DE0, DE300, DE450, and DE600. For any combination, there were 5 plants for replications. Hourly averaged $\mathrm{O}_{3}$ concentrations were obtained through the logging interval of 30 min with a Thermo-Electron Model 49i analyzer (Model 49i, Thermo 


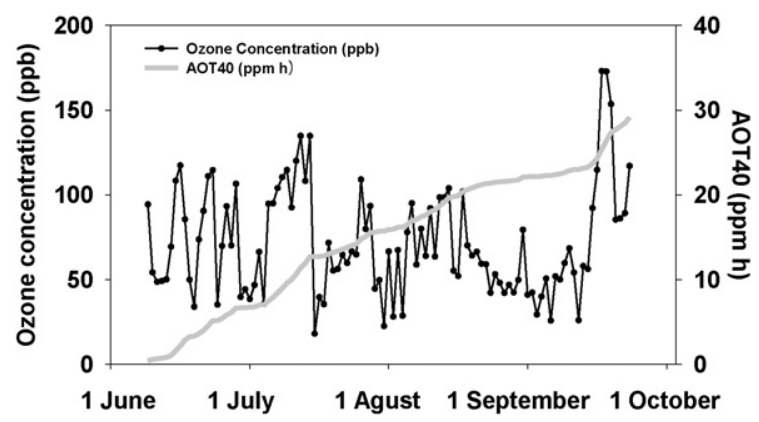

Fig. 1. Variations in $8 \mathrm{~h}(9: 00-17: 00)$ mean $\mathrm{O}_{3}$ concentrations and AOT40 during the study period from June 9 to September 21.

Scientific, USA) during 9 June to 21 September. The hourly averages were used to calculate AOT40 value for $\mathrm{O}_{3}$ exposure.

\subsection{Parameter measurements}

\subsubsection{Photosynthetic parameters}

Gas exchange and chlorophyll $a$ fluorescence parameters were measured with a portable photosynthetic system fitted with a 6400-40 leaf chamber fluorometer (LI-6400XT, LICOR Corp., USA) in all plants on September 7. During the measurements, photosynthetic active radiation (PAR) was set at $1200 \mu \mathrm{mol} \mathrm{m} \mathrm{m}^{-2} \mathrm{~s}^{-1}, \mathrm{CO}_{2}$ levels at $400 \mathrm{ppm}$, block temperature at $30{ }^{\circ} \mathrm{C}$, and relative humility (RH) between $45 \%$ and 55\%. Measurements were carried out between 9:00 and 12:00 h in sunny day on fully expanded leaves at upper layers of plants. The following parameters were measured: light-saturated rate of $\mathrm{CO}_{2}$ assimilation $\left(A_{s a t}\right)$, stomatal conductance $\left(g_{s}\right)$, transpiration rate $\left(T_{r}\right)$, actual photochemical efficiency of PSII in the saturated light $\left(F_{v}{ }^{\prime} / F_{m}{ }^{\prime}\right)$, quenching of photochemical efficiency of PSII ( $q \mathrm{P})$ and actual photochemical efficiency of PSII in the light (PhiPSII). Water use efficiency (WUE) was expressed as the ratio of $A_{\text {sat }}$ and $T_{r}$. At 92 DAP, the automatic program in the LI-6400 photosynthesis system was used to perform the photosynthesis and intercellular $\mathrm{CO}_{2}(\mathrm{~A} / \mathrm{Ci})$ curves. Measurements were taken by changing $\mathrm{CO}_{2}$ levels in leaf chamber fluorometer in 11 steps (380, 300, 200, 100, 50, 400, 600, 800, 1000, 1200, 1500 ppm) under the same PAR, T, and RH conditions with $A_{\text {sat }}$ measurements. The maximum rates of Rubisco carboxylation $\left(V_{\mathrm{cmax}}\right)$ and the maximum electron transport rates $\left(J_{\max }\right)$ were subsequently calculated according to the methods described by Sharkey et al. (2007).

\subsubsection{Leaf pigment, antioxidant, and malondialdehyde (MDA) contents}

Leaf samples for pigment, antioxidant, and MDA contents were collected from fully expanded leaves at upper layers on the same day for photosynthesis measurements. The sampled leaves discs for pigment were extracted with $2 \mathrm{ml} \mathrm{95 \%} \mathrm{ethanol} \mathrm{solution} \mathrm{in} \mathrm{the} \mathrm{dark} \mathrm{for} \mathrm{about}$ $72 \mathrm{~h}$ at $4{ }^{\circ} \mathrm{C}$ until totally fading. The extract was then assayed for chlorophyll (Chl) and carotenoid (Car) contents by using the specific absorption coefficients of Lichtenthaler (1987). Samples from two leaves of all plants were punched, frozen immediately in liquid $\mathrm{N}$, and stored at $-80^{\circ} \mathrm{C}$ until analysis. MDA content, which is related with the level of lipid peroxidation in the leaves, was analyzed according to the method of Heath and Packer (1968). Ascorbic acid was determined following to Gillespie and Ainsworth (2007). Total antioxidant capacity (TAC) was conducted following the method of Benzie and Strain (1996).

\subsubsection{Relative growth rates and biomass}

From 20 June to 21 September, plant heights and stem diameters were measured once per month. Relative growth rate (RGR) was

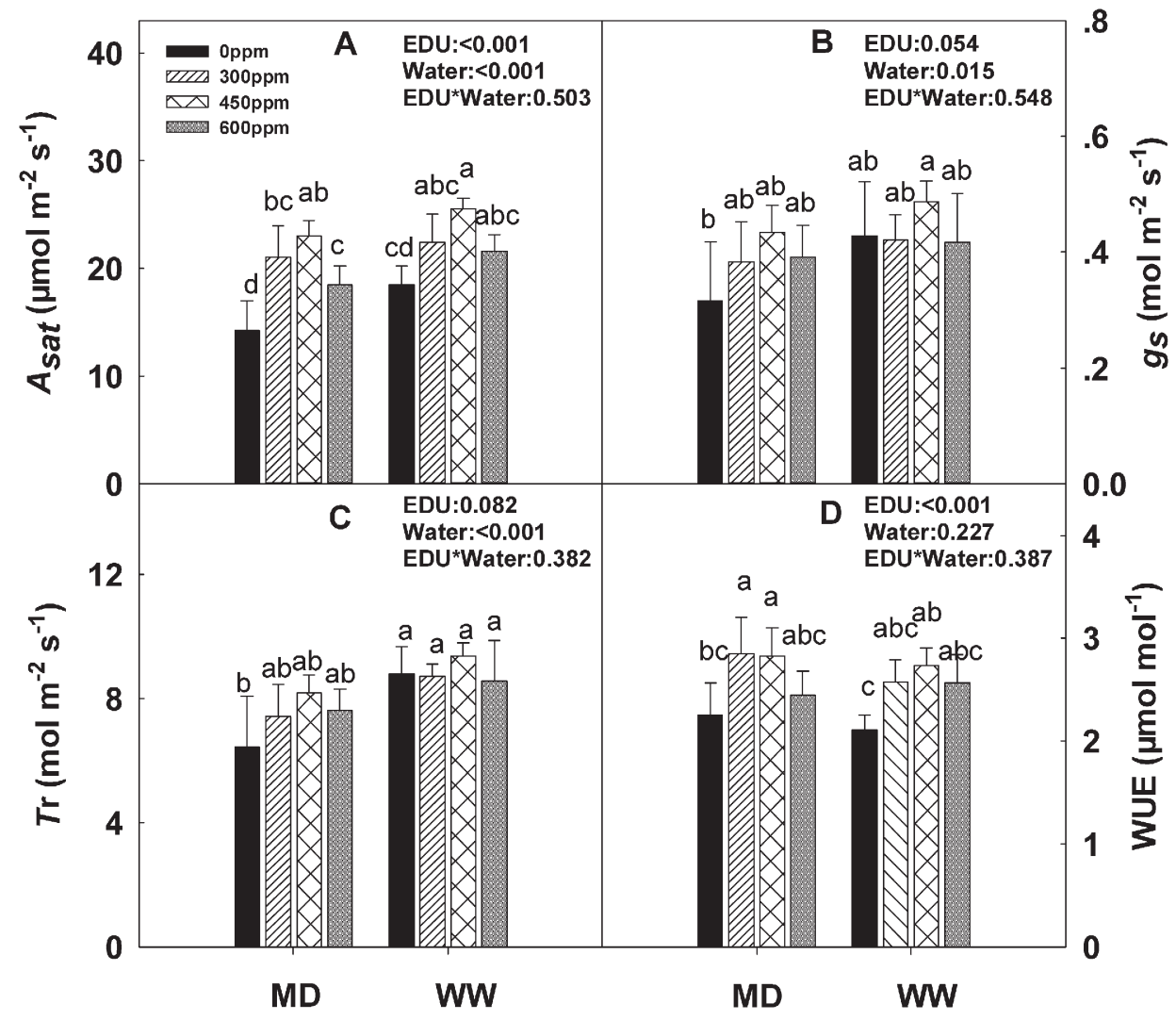

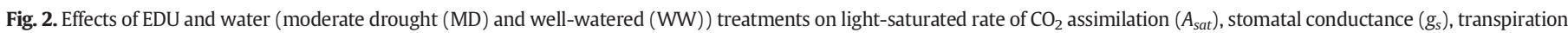
rate $\left(T_{r}\right)$, and water use efficiency (WUE) of $P$. cathayana in ambient $\mathrm{O}_{3}$ concentration. Different letters indicate significant differences between EDU and water. 
calculated as:

$$
\begin{aligned}
R G R & =\left(\ln \left(H_{2}\right)-\ln \left(H_{1}\right)\right) /\left(t_{2}-t_{1}\right) \text { or } R G R \\
& =\left(\ln \left(D_{2}\right)-\ln \left(D_{1}\right)\right) /\left(t_{2}-t_{1}\right),
\end{aligned}
$$

where $H_{1} / H_{2}$ and $D_{1} / D_{2}$ were the plant heights and stem diameters, respectively, measured at beginning and end, and $t_{1}$ and $t_{2}$ were the time points at which the data were measured (Bortier et al., 2000).

All plants were harvested at 105 DAP when the leaves began to senescence. Shoot and root dry biomass were also determined after drying the different parts of the plants at $80{ }^{\circ} \mathrm{C}$ until constant weight. Root/ shoot ratio was calculated by the dry weight of the shoot and root. All harvested leaves per plant were grounded and used to analyze for nitrogen $(\mathrm{N})$ using an elemental analyzer (Vario EL, Elementar, Germany).

\subsection{Statistical analysis}

The data for each dependent variable were subjected to the two-way analysis of variance with mixed linear model to test the effects of EDU, water, and their interactions using JMP software (SAS Institute, USA). Tukey's HSD test was applied to identify significant differences between water or among EDU treatments. A difference between the means was considered significant if $P<0.05$. Data shown in figures were means $\pm S D(n=4$ or 5$)$.

\section{Results}

\subsection{Ozone exposure}

During the experimental period (June 9 to September 21), the average ambient $\mathrm{O}_{3}$ concentration was $71.7 \mathrm{ppb}$ (between 9:00 and 17:00) and ranged between 18.0 and $173.1 \mathrm{ppb}$. Peak $1 \mathrm{~h}$ values at June, July, August, and September were 117.5, 134.9, 104, and $173.1 \mathrm{ppb}$, respectively. For the 105 days of the experiment, AOT40 reached $29.2 \mathrm{ppm} \mathrm{h}$ at end of the experiment as shown in Fig. 1.

\subsection{Photosynthesis and pigments}

$\mathrm{O}_{3}$-induced injury was not quantified in this study. Almost all nonEDU plants showed the typical $\mathrm{O}_{3}$ symptoms, but only a few leaves in some EDU-treated plants. From Fig. 2A, both water and EDU had significant effects on $A_{\text {sat }}$, but the interactive effect was not significant $(P=$ 0.503 ). EDU significantly increased $A_{\text {sat }}$ by $32.8 \%$ and $48.7 \%$ for E300 and E450, respectively. However, MD significantly decreased $A_{\text {sat }}$ by $12.9 \%$ compared with WW plants. $g_{s}$ had the similar trends with $A_{\text {sat }}$. $T_{r}$ was not significantly affected by EDU treatments (Fig. 2C). But MD significantly reduced $T_{r}$, e.g. DE0 was lower than WE0 by $26.8 \%$. EDU significantly increased WUE $(P<0.001)$, and MD had an increasing trend although it was not significant (Fig. 2D). The highest WUE was found in the DE300, which was 35.3\% higher than WEO.

EDU and MD significantly affected chlorophyll $a$ fluorescence parameters $\left(F_{v}{ }^{\prime} / F_{m}{ }^{\prime}\right.$ and PhiPSII $)$ while there was no significant interaction (Fig. 3). $F_{v}{ }^{\prime} / F_{m}{ }^{\prime}$ was declined slightly (4.7\%) under MD and increased significantly (17.3 and $18.6 \%$ ) in DE300 and DE450 relative to DE0 (Fig. 3A). The PhiPSII of MD plants was $11.3 \%$ lower than WW plants across EDU treatments. PhiPSII was 23.1\% higher in E450 than E0 (Fig. 3B) across water treatments. EDU had no effect on $q \mathrm{P}(P=$ 0.182 ), but drought significantly decreased $q \mathrm{P}(7.0 \%)$ (Fig. $3 \mathrm{C}$ ).

Changes in $V_{\text {cmax }}$ by EDU or MD were consistent with those in $J_{\max }$. From Fig. $4, V_{\text {cmax }}$ and $J_{\max }$ were significantly increased in WE450 plants ( $V_{\text {cmax }}$ by $22.8 \%$ and $J_{\max }$ by $30.1 \%$ ) relative to WE0. MD significantly decreased $V_{\text {cmax }}$ and $J_{\max }$ by $20.4 \%$ and $34.3 \%$, respectively. Although EDU and MD significantly affected $V_{\text {cmax }}$ and $J_{\text {max }}$, there was no significant interaction.

EDU and MD significantly changed chlorophyll and carotenoid contents (Fig. 5). Significant interaction of EDU and water on Chl a

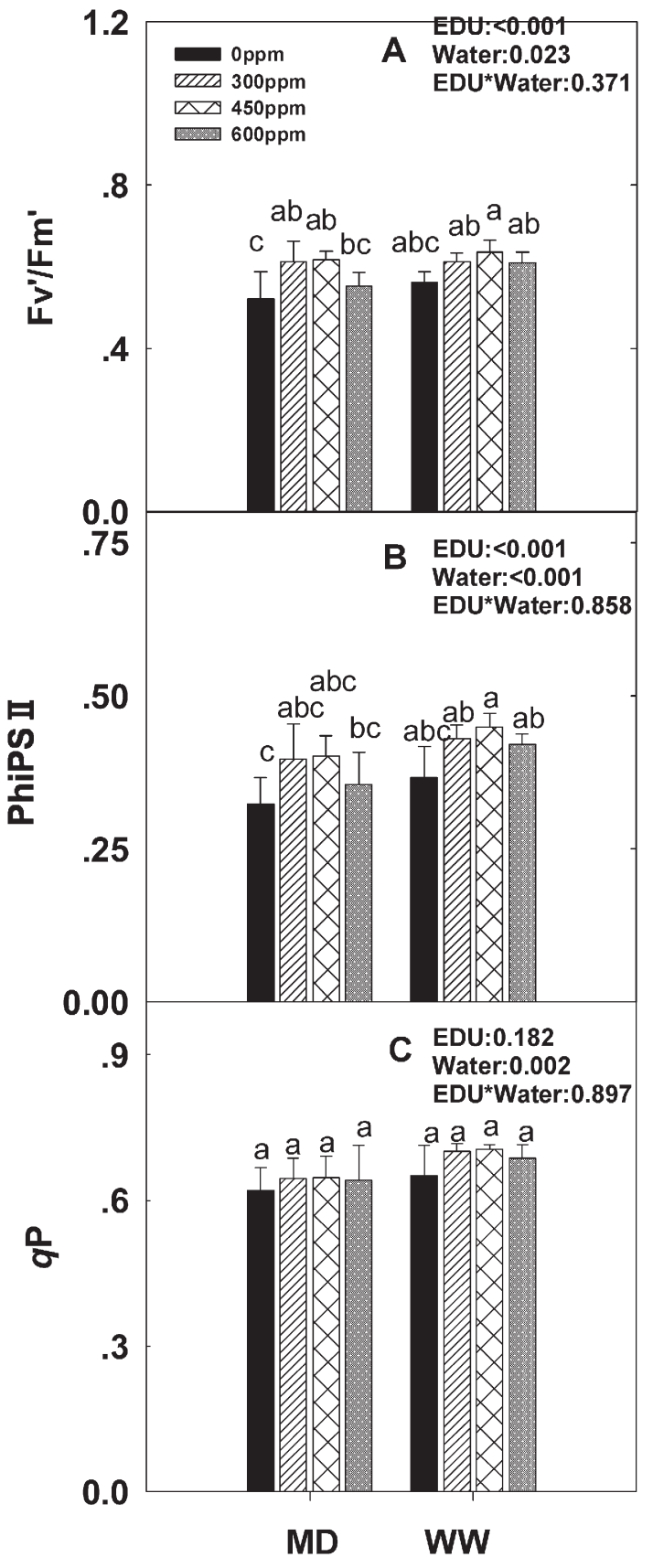

Fig. 3. Effects of EDU and water (moderate drought (MD) and well-watered (WW)) treatments on chlorophyll $a$ fluorescence parameters (actual photochemical efficiency of PSII in the saturated light $\left(F_{v}{ }^{\prime} / F_{m^{\prime}}{ }^{\prime}\right)$, quenching of photochemical efficiency of PSII ( $q$ P) and actual photochemical efficiency of PSII in the light (PhiPSII)) of P. cathayana in ambient $\mathrm{O}_{3}$ concentration. Different letters indicate significant differences between EDU and water.

was found $(P=0.009)$. With the increase of EDU concentration, Chl a showed an increasing trend until $450 \mathrm{ppm}$ and then a decrease at 600 ppm. DE450 was significantly 19.9\% lower than WE450 in Chl a, but no significant drought effects were found in other EDU concentrations (Fig. 5A). Chl b had the same response trend to EDU or drought with Chl a (Fig. 5B). Chl b was increased by $35.2 \%$ in E450 relative to E0 and decreased by $9.4 \%$ by drought. Car was significantly increased by $17.0 \%$ across two water treatments when EDU was 450 ppm. MD decreased Car by $15.5 \%$. However, there was no significant interaction between $\mathrm{O}_{3}$ and water on $\mathrm{Car}(P=0.719)$ (Fig. 5C). Moreover, neither EDU nor MD significantly affected foliar nitrogen concentration (Fig. 5D). 


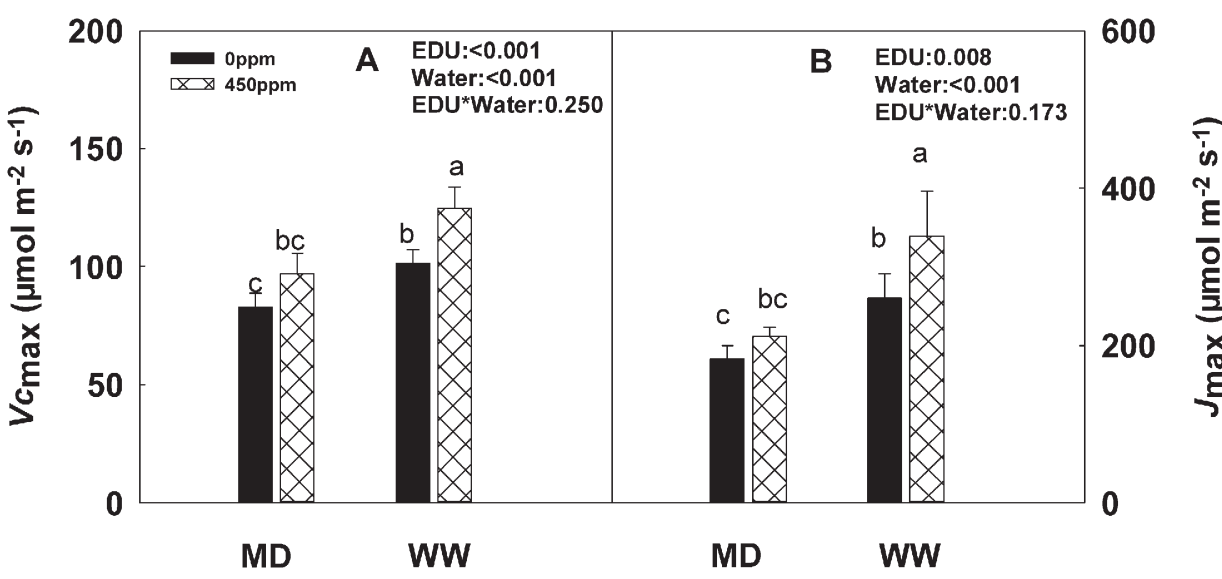

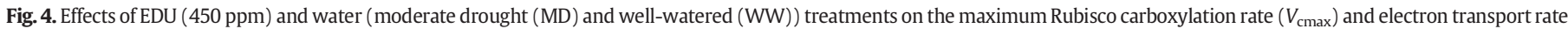
$\left(J_{\max }\right)$ of $P$. cathayana in ambient $\mathrm{O}_{3}$ concentration. Different letters indicate significant differences between EDU and water.

\subsection{Antioxidant and MDA contents}

EDU and MD showed significant differences in ascorbate (AsA) and MDA as well as in TAC (Fig. 6). When both water treatments were considered together, AsA and MDA showed a decreased trend from E0 to E450 and then an increase at E600 (Fig. 6A\&B), and E450 significantly decreased AsA and MDA contents by $29.0 \%$ and $32.1 \%$, respectively. Considering MD, AsA in DE450 was 33.0\% higher than that in WE450 while MDA in DE600 was significantly $15.9 \%$ higher than that in WE600. TAC was increased by $8.1 \%, 19.0 \%$, and $24.9 \%$, respectively, when EDU was 300, 450, and 600 ppm. MD increased TAC by $8.8 \%$ (Fig. 6D).

\subsection{Relative growth rates and biomass parameters}

Both EDU and MD had significant effects on $P$. cathayana $(P<0.05)$. EDU significantly increased RGR1 of height by 53.6\% (E300), 107.1\% (E450), and 60.3\% (E600), and RGR2 of stem diameter by $30.8 \%$ (E300), 59.5\% (E450), and 38.0\% (E600) (Fig. 7). MD had a greater reduction in RGR2 $(P=0.008)$ than RGR1 $(P=0.034)$. However, the interaction of EDU and MD was significant in RGR1 (DE450 was 15.3\% lower than WE450), but not in RGR2. (Fig. 7).

From Fig. 8, biomass parameters were significantly influenced by both EDU and MD. EDU significantly increased the shoot dry weight per plant by $53.7 \%, 85.5 \%$, and $47.4 \%$, and root weight by $26.5 \%, 41.7 \%$,

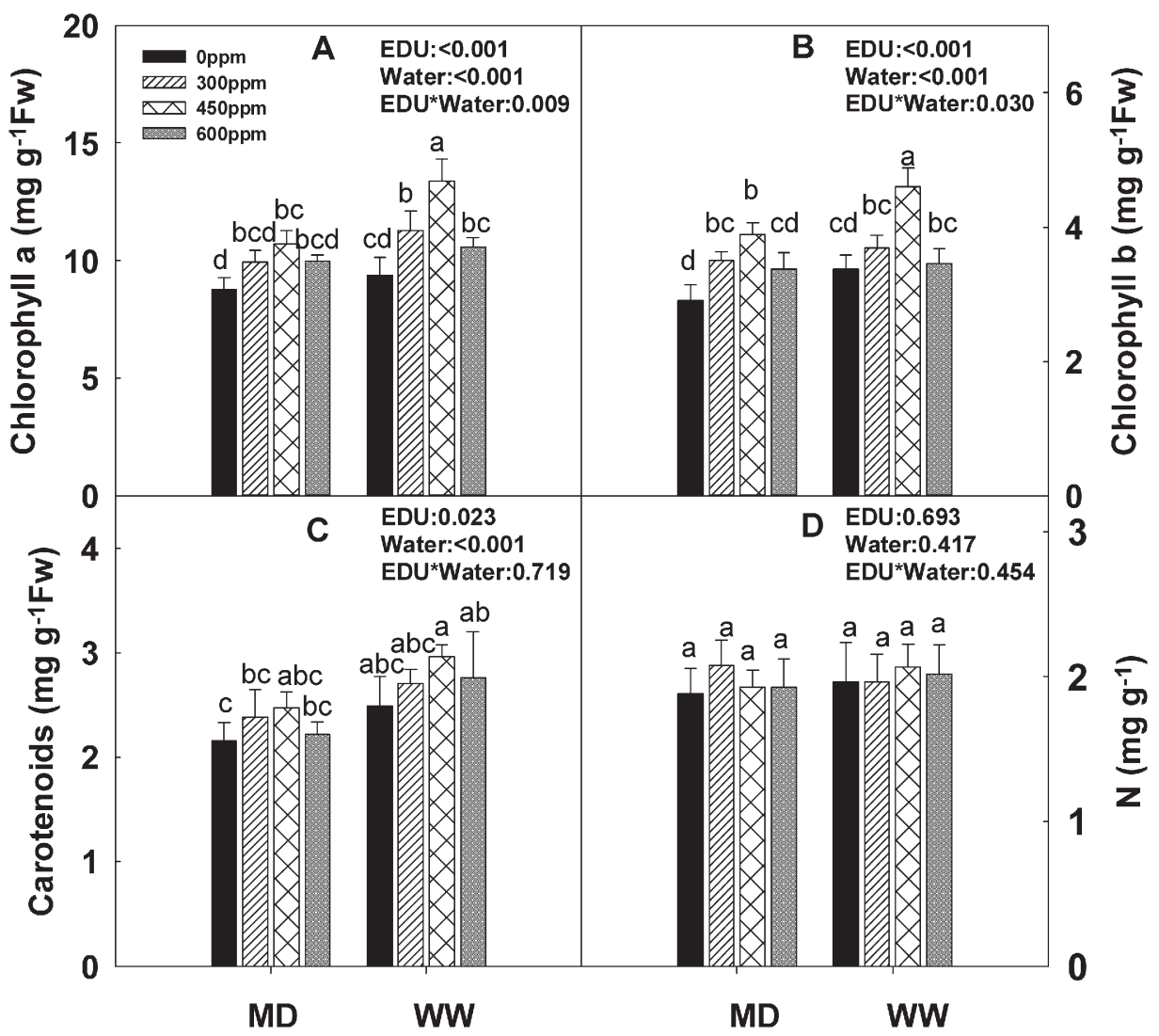

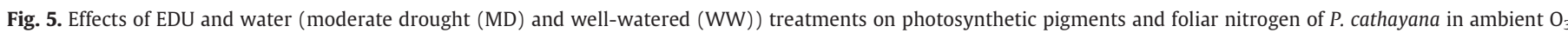
concentration. Different letters indicate significant differences between EDU and water. 


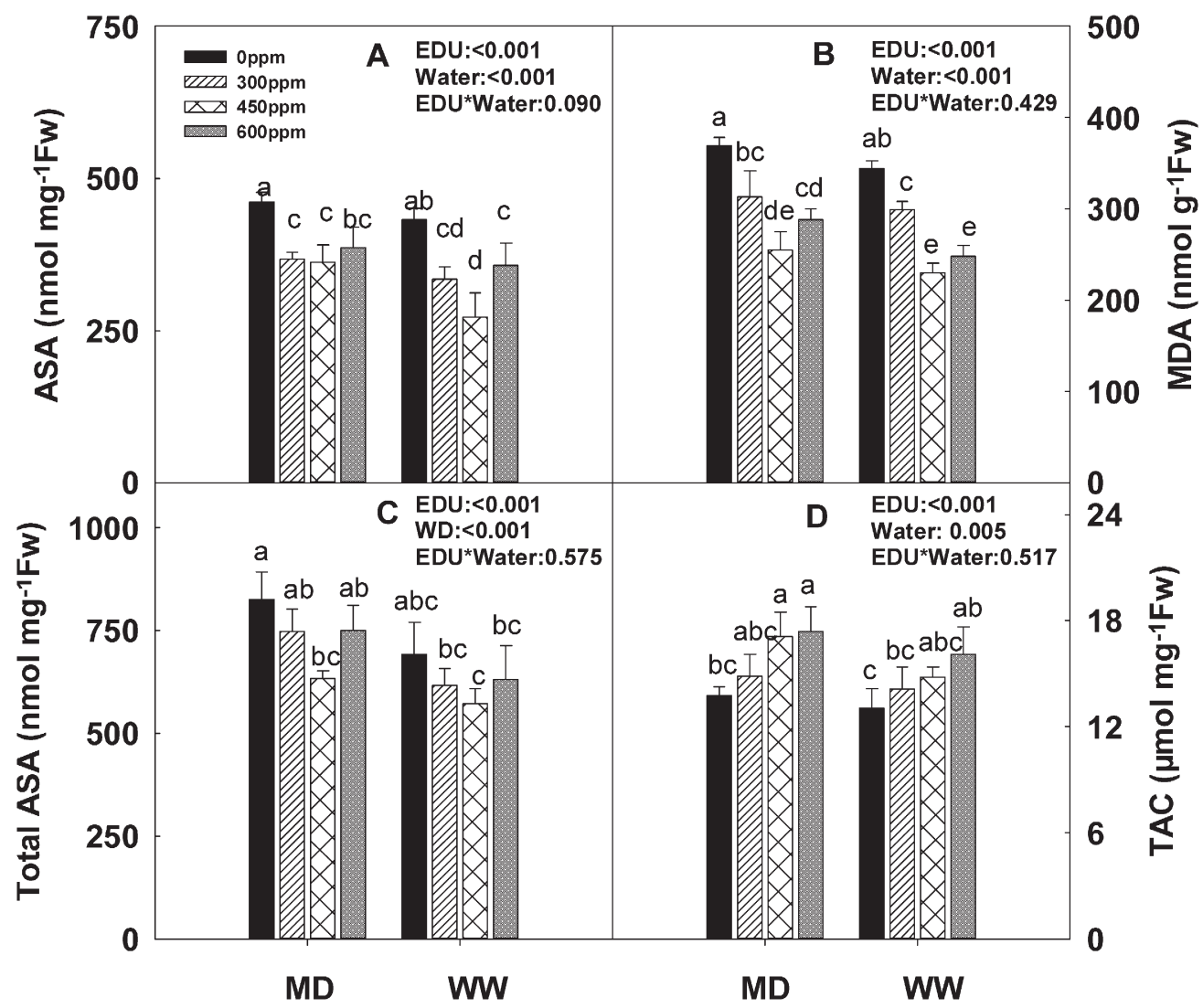

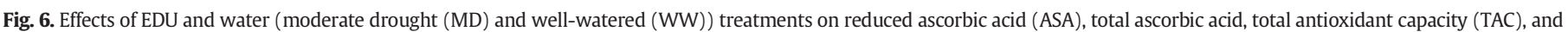
malondialdehyde (MDA) contents of $P$. cathayana in ambient $\mathrm{O}_{3}$ concentration. Different letters indicate significant differences between EDU and water.

and $24.3 \%$ in E300, E450, and E600, respectively, when both water treatments were considered together. However, MD significantly decreased shoot and root weight by $33.0 \%$ and $11.0 \%$, respectively. Effects of EDU on total biomass differed significantly between the two water treatments $(P=0.041)$ (Fig. 8), as indicated that E450 increased total biomass by $67.8 \%$ at WW while $51.7 \%$ at MD in comparison with corresponding E0.

\section{Discussion}

In our study, the average $\mathrm{O}_{3}$ concentration was as high as $71.7 \mathrm{ppb}$ in the northwest of Beijing with the highest hourly concentration above $173 \mathrm{ppb}$. Accordingly, the AOT40 value reached $29.2 \mathrm{ppm}$ h, much higher than 5 ppm h over 6 months set as the critical $\mathrm{O}_{3}$ levels for the protection of forest by UNECE (LRTAP Convention, 2010). Also, it has exceeded the $\mathrm{O}_{3}$ threshold of $12 \mathrm{ppm}$ h for poplar species defined by Hu et al. (2015). High $\mathrm{O}_{3}$ concentration also occurred in 2014 (Yuan et al., 2015), suggesting that Beijing has been a hotspot of $\mathrm{O}_{3}$ pollution. And this situation cannot be changed in the short term because $\mathrm{O}_{3}$ precursors (mainly NOx) are currently increasing in China at an annual rate of 5\% (Feng et al., 2015).

EDU is widely used to protect plants from $\mathrm{O}_{3}$ injury and is a useful approach to assess if ambient $\mathrm{O}_{3}$ is high enough to induce damage to plants (Feng et al., 2010; Manning et al., 2011; Agathokleous et al., 2015). It was shown that EDU concentration in the leaf increased over the 21-day period when the leaf was not washed after the foliar spray application, while it decreased when the leaf was washed after the application (Pasqualini et al., 2016). Furthermore, EDU does not translocate to newly formed leaves (Weidensaul, 1980). Therefore, the EDU with repeated foliar sprays are needed. In this experiment, the EDU was applied in total 5 times with an interval of 2 weeks. At the end of our experiment, EDU significantly increased photosynthesis, growth, and biomass, but reduced lipid peroxidation under ambient $\mathrm{O}_{3}$ concentration, suggesting that the selected poplar species has been negatively affected by high ambient $\mathrm{O}_{3}$ concentration in Beijing. However, EDU can be toxic at higher concentration (Agathokleous et al., 2016). This study showed that $450 \mathrm{ppm}$ EDU applied as foliar spray is better than other concentrations to protect the poplar against $\mathrm{O}_{3}$, which is consistent with snap bean (Yuan et al., 2015). EDU increased $A_{\text {sat }}$ by sustaining higher $V_{\text {cmax }}, J_{\max }$, and fluorescence parameters in the light, and chlorophyll and carotenoids contents. Higher chlorophyll content in EDU compared with non-EDU-treated plants suggests that EDU delayed foliar senescence by reducing oxidative stress. Similar results were also found in soybean and snap bean (Rai et al., 2015; Yuan et al., 2015). By maintaining higher carotenoids concentration, chlorophyll damage due to $\mathrm{O}_{3}$ is also avoided because carotenoids provide photoprotection and are antioxidant molecules (Demmig-Adams and Adams, 1996). Although EDU is a nitrogen-containing compound, the foliar nitrogen content was not altered significantly in different EDU treatments (Fig.5). Similar finding was also found in several crop and tree species studied (Paoletti et al., 2009). In a review, Manning et al. (2011) does not support the role of nitrogen in EDU for protection against high $\mathrm{O}_{3}$ concentrations.

In our study, EDU significantly increased RGR, shoot dry weight, root dry weight, and total biomass. A meta-analysis indicated that EDU significantly increased above-ground biomass in trees by $6.5 \%$ and crop yield by $15 \%$ in comparison with non-EDU-treated plants (Feng et al., 2010). However, across two water treatments, biomass increases (62\%) in P. cathayana are much higher than the averaged responses of tree species (6.5\%) to EDU (Feng et al., 2010). The large difference may be strongly related with high $\mathrm{O}_{3}$ concentration at experimental site, tree age, and the selected $P$. cathayana which is much sensitive to $\mathrm{O}_{3}$. 


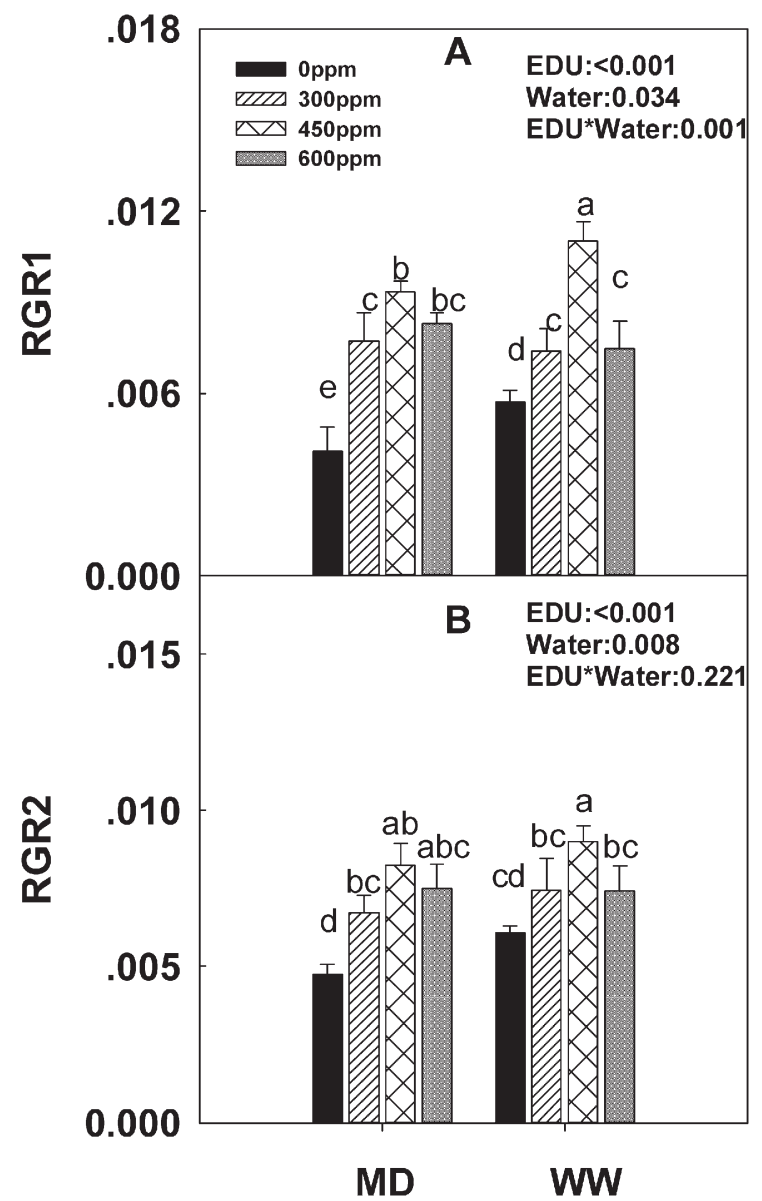

Fig. 7. Effects of EDU and water (moderate drought (MD) and well-watered (WW)) treatments on relative growth rate (RGR1 and RGR2 were calculated based on plants height and stem diameters, respectively) of $P$. cathayana in ambient $\mathrm{O}_{3}$ concentration. Different letters indicate significant differences between EDU and water.

Agathokleous et al. (2015) have demonstrated that sensitive cultivars are more responsive to EDU treatments from several experiments. However, the effect of EDU on the ratio of root and shoot was not significant, suggesting that EDU increased root and shoot growth at a similar rate although EDU was applied as foliar spray. Similar result was also found in a long-term ambient $\mathrm{O}_{3}$ exposure in Italy (Carriero et al., 2015).

The protection mechanism of EDU on plants is not totally understood (Paoletti et al., 2009; Manning et al., 2011). Manning et al. (2011) mentioned that $\mathrm{O}_{3}$ penetration into the apoplast is known to induce the formation of secondary toxicant (i.e. reactive oxygen species), some of which could be scavenged by EDU. However, direct chemical scavenging has not been demonstrated so far. AsA is a key metabolite in antioxidant system that protects plants from reactive oxygen species, acting as a chemical scavenger and/or as a substrate of extracellular enzymes. In this study, EDU induced significant reduction in reduced AsA and total AsA, indicating that more AsA in EDU treatments was used to detoxify $\mathrm{O}_{3}$, hence less lipid peroxidation in EDU-treated plants. EDU did not affect AsA contents in ash (Fraxinus excelsior), snap bean, and tropical wheat (Triticum aestivum L.) (Paoletti et al., 2008; Singh et al., 2009; Yuan et al., 2015).

In the hot and dry summer of Beijing, drought was a predominant factor affecting photosynthetic activity of poplars. In actual field conditions, severe drought events occur infrequently, while moderate drought is common in the world and its frequency is increasing due to global warming and limited water resources (Piao et al., 2010). To avoid unrealistic long periods of drought, the plants were irrigated at
1-2 day intervals in the late afternoon, which induced a dryingrewatering cycle, especially in summer. From current study, moderate drought significantly reduced most parameters $\left(A_{\mathrm{sat}}, g_{\mathrm{s}}\right.$, Tr, chlorophyll fluorescence, photosynthetic pigment contents, $V c_{\max }$, and $J_{\max }$, relative growth rate and biomass) and increased the antioxidant contents across EDU treatments. These results are in general agreement with the recognized consequences on plants induced by drought (Pollastrini et al., 2014). By using eddy-covariance system, Zhou et al. (2013) also found that poplar plantations were sensitive to drought by reducing carbon exchange during canopy development. Trees were more sensitive to severe drought stress than shrubs due to lower capacities of osmotic adjustment and antioxidant protection (Liu et al., 2011). Different tree species had specific limiting processes controlling the photosynthetic capacity under drought (Zhou et al., 2015). Also, Alexou (2013) indicated that responses of Aleppo pine (Pinus halepensis Mill.) to drought may depend significantly on developmental stage, and the duration of drought had more effects than its severity. In this study, all measurements were conducted during fast growing stages with higher stomatal conductance and photosynthesis, suggesting the fast growing stage is more sensitive to drought than other stages. Furthermore, drought can induce a deeper rooting system so that the trees could get more water supplies from deeper water pools (Eilmann and Rigling, 2012). In our study, drought significantly reduced the biomass of root and had no effects on root/shoot, possibly due to mild drought level and a towing basin under each pot, which was used to prevent roots growing into the ground.

This is the first study on the interaction between EDU and drought on plants growing under the ambient air condition. Among all variables, only chlorophyll contents, RGR1, and total biomass showed significant interaction between EDU and drought, as indicated by much larger effects of EDU at 450 ppm on WW plants than MD plants. Li et al. (2015) indicated that the well-watered plants suffered more $\mathrm{O}_{3}$ injury than drought-treated plants because of stomata closure and anatomical changes by drought. However, current results indicated that moderate drought at any EDU treatment did not significantly induce stomatal closure in P. cathayana compared with corresponding well-watered plants, possibly because drought level was not severe. Besides $g_{s}$, effects of $\mathrm{O}_{3}$ on plants also depend on antioxidative enzymes activity and antioxidant contents ( $\mathrm{Li}$ et al., 2016; Matyssek et al., 2007). No significant interaction between EDU and water was found in the contents of antioxidants such as ASA, total ASA, and TAC, indicating that EDU did not enhance the detoxification under WW relative to MD. Therefore, most variables including photosynthetic parameters and biomass did not show significant interactions between EDU and water. It can be concluded that the protection of EDU against $\mathrm{O}_{3}$ was not affected by moderate drought. Similar results with no significant interaction between $\mathrm{O}_{3}$ and drought were also found in tree species such as Betula pendula, Picea abies (Pearson and Mansfield, 1994; Karlsson et al., 2002), but $\mathrm{O}_{3}$ damage enhanced by less severe drought was also observed compared to that of well-watered plants (Pääkkönen et al., 1998). Actually, the interaction of $\mathrm{O}_{3}$ and drought is very complex and determined by many aspects, such as species, the sequence, degree, and duration of both factors.

In conclusion, EDU was shown to protect the $\mathrm{O}_{3}$-sensitive poplar (Populus cathayana) from the ambient $\mathrm{O}_{3}$ in the field near Beijing, China. This protection was effective for well-watered plants and those experiencing moderate drought. Photosynthetic performance was improved as well as higher antioxidant capacity, resulting in increased biomass. Populus cathayana could be a very useful bio-indicator for phytotoxic concentrations of $\mathrm{O}_{3}$ under ambient conditions when the performance of EDU-treated and non-EDU-treated plants are compared.

\section{Acknowledgements}

This study has been funded by the Hundred Talents Program, Chinese Academy of Science, and Key Laboratory of Urban Agriculture (North) of Ministry of Agriculture, China. 


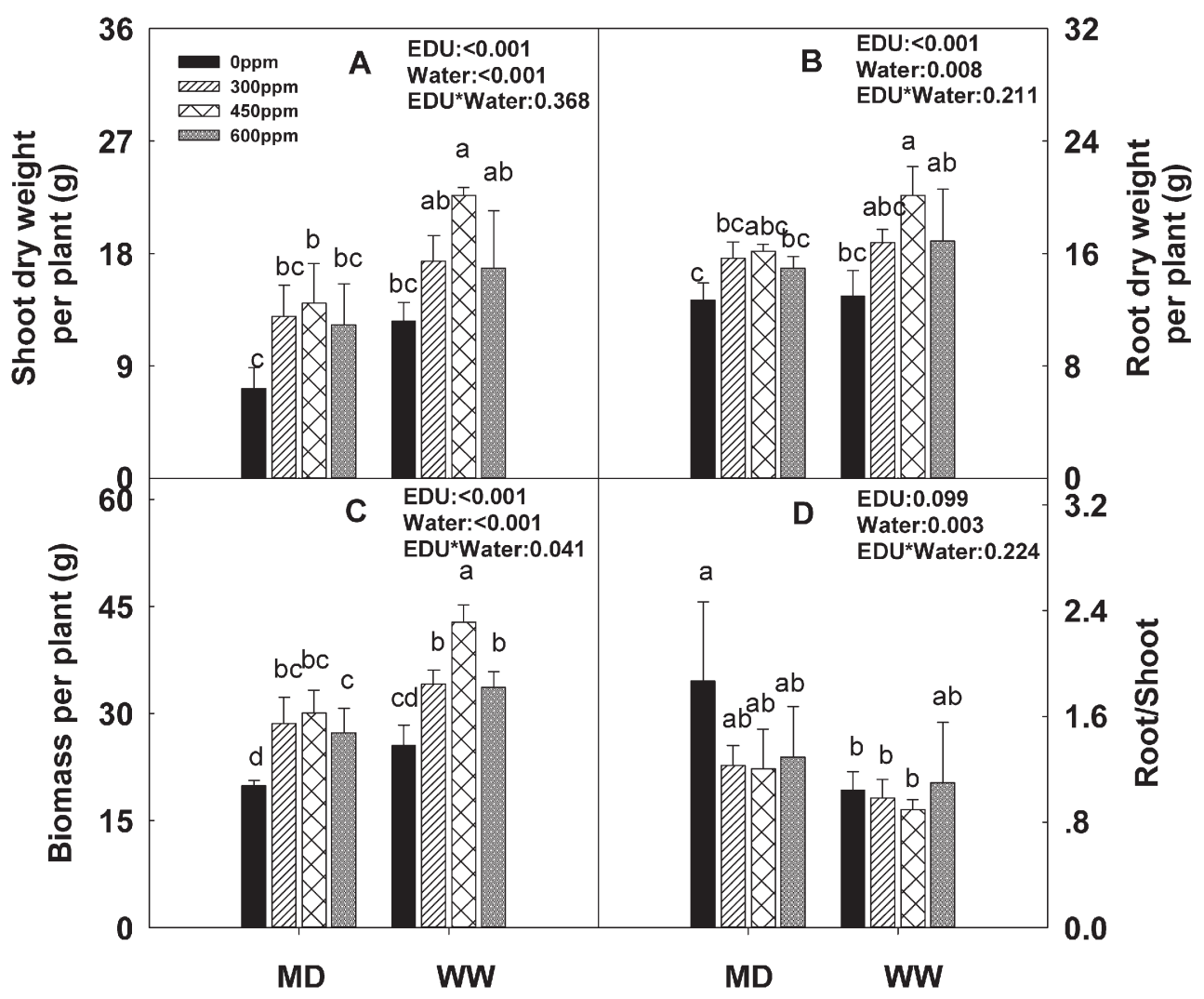

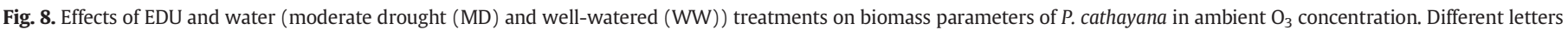
indicate significant differences between EDU and water.

\section{References}

Agathokleous, E., Koike, T., Watanabe, M., Hoshika, Y., Saitanis, C.J., 2015. Ethylene-di-urea (EDU), an effective phytoprotectant against $\mathrm{O}_{3}$ deleterious effects and a valuable research tool. J. Agric. Meteorol. 71, 185-195.

Agathokleous, E., Mouzaki-Paxinou, A.C., Saitanis, C.J., Paoletti, E., Manning, W.J., 2016. The first toxicological study of the antiozonant and research tool ethylene diurea (EDU) using a Lemna minor L. bioassay: hints to its mode of action. Environ. Pollut. 213 996-1006.

Alexou, M., 2013. Development-specific responses to drought stress in Aleppo pine (Pinus halepensis Mill.) seedlings. Tree Physiol. 33, 1030-1042.

Benzie, I.F.F., Strain, J.J., 1996. The ferric reducing ability of plasma (FRAP) as a measure of "antioxidant power": the FRAP assay. Anal. Biochem. 239, 70-76.

Bortier, K., De Temmerman, L., Ceulemans, R., 2000. Effects of ozone exposure in open-top chambers on poplar (Populus nigra) and beech (Fagus sylvatica): a comparison. Environ. Pollut. 109, 509-516.

Carnahan, J.E., Jenner, E.L., Wat, E.K.W., 1978. Prevention of ozone injury to plants by a new protectant chemical. Phytopathology 68, 1225-1229.

Carriero, G., Emiliani, G., Giovannelli, A., Hoshika, Y., Manning, W.J., Traversi, M.L., Paoletti, E., 2015. Effects of long-term ambient ozone exposure on biomass and wood traits in poplar treated with ethylenediurea (EDU). Environ. Pollut. 206, 575-581.

Eilmann, B., Rigling, A., 2012. Tree-growth analyses to estimate tree species' drought tolerance. Tree Physiol. 32, 178-187.

Feng, Z., Hu, E., Wang, X., Jiang, L., Liu, X., 2015. Ground-level $\mathrm{O}_{3}$ pollution and its impacts on food crops in China: a review. Environ. Pollut. 199, 42-48.

Feng, Z., Sun, J., Wan, W., Hu, E., Calatayud, V., 2014. Evidence of widespread ozoneinduced visible injury on plants in Beijing, China. Environ. Pollut. 193, 296-301.

Feng, Z., Wang, S., Szantoi, Z., Chen, S., Wang, X., 2010. Protection of plants from ambient ozone by applications of ethylenediurea (EDU): a meta-analytic review. Environ. Pollut 158, 3236-3242.

Gillespie, K.M., Ainsworth, E.A., 2007. Measurement of reduced, oxidized and total ascorbate content in plants. Nat. Protoc. 2, 871-874.

Heath, R.L., Packer, L., 1968. Photoperoxidation in isolated chloroplasts: I. Kinetics and stoichiometry of fatty acid peroxidation. Arch. Biochem. Biophys. 125, 189-198.

Hoshika, Y., Pecori, F., Conese, I., Bardelli, T., Marchi, E., Manning, M.J., Badea, O., Paoletti, E., 2013. Effects of a three-year exposure to ambient ozone on biomass allocation in poplar using ethylenediurea. Environ. Pollut. 180, 299-303.

Hu, E., Gao, F., Xin, Y., Jia, H., Li, K., Hu, J., Feng, Z., 2015. Concentration- and flux-based ozone dose-response relationships for five poplar clones grown in North China. Environ. Pollut. 207, 21-30.
Karlsson, P.E., Medin, E.L., Selldén, G., Wallin, G., Ottosson, S., Pleijel, H., Skärby, L., 2002. Impact of ozone and reduced water supply on the biomass accumulation of Norway spruce saplings. Environ. Pollut. 119, 237-244.

Li, L., Manning, W.J., Tong, L., Wang, X.K., 2015. Chronic drought stress reduced but not protected Shantung maple (Acer truncatum Bunge) from adverse effects of ozone $\left(\mathrm{O}_{3}\right)$ on growth and physiology in the suburb of Beijing, China. Environ. Pollut. 3, 79-87.

Li, P. Calatayud, V., Gao, F. Uddling J., Feng Z7 Z, 2016. Differences in ozone sensitivity among woody species are related to leaf morphology and antioxidant levels. Tree Physiol. http://dx.doi.org/10.1093/treephys/tpw042.

Lichtenthaler, H.K., 1987. Chlorophylls and carotenoids: pigments of photosynthetic biomembranes. Methods Enzymol. 148, 350-382.

Liu, C.C., Liu, Y.G., Guo, K., Fan, D.Y., Li, G.G., Zheng, Y.R., Yu, L.F., Yang, R., 2011. Effect of drought on pigments, osmotic adjustment and antioxidant enzymes in six woody plant species in karst habitats of southwestern China. Environ. Exp. Bot. 71, 174-183.

Liu, Y.L., Pan, Z.H., Zhuang, Q.L., Miralles, D.G., Teuling, A.J., Zhang, T.L., An, P.L., Dong, Z.Q., Zhang, J.T., He, D., Wang, L.W., Pan, X.B., Bai, W., Niyogi, D., 2015. Agriculture intensifies soil moisture decline in Northern China. Sci. Rep. 5, 11261. http://dx.doi.org/ $10.1038 /$ srep 11261.

LRTAP Convention, 2010. Mapping Critical Levels for Vegetation, Manual on Methodologies and Criteria for Modeling and Mapping Critical Loads \& Levels and Air Pollution Effects, Risk and Trends. Chapter 3. Available from: http://www.icpvegetation.ceh.ac.uk.

Manning, W.J., Flagler, R.B., Frenkel, M.A., 2003. Assessing plant response to ambient ozone: growth of ozone-sensitive loblolly pine seedlings treated with ethylenediurea or sodium erythorbate. Environ. Pollut. 126, 73-81.

Manning, W.J., Paoletti, E., Sandermann Jr., H., Ernst, D., 2011. Ethylenediurea (EDU): a research tool for assessment and verification of the effects of ground level ozone on plants under natural conditions. Environ. Pollut. 159, 3283-3293.

Matyssek, R., Bytnerowicz, A., Karlsson, P.E., Paoletti, E., Sanz, M., Schaub, M., Wieser, G., 2007. Promoting the $\mathrm{O}_{3}$ flux concept for European forest trees. Environ. Pollut. 146, 587-607.

Novak, K., Schaub, M., Fuhrer, J., Skelly, J.M., Hug, C., Landolt, W., Bleuler, P., Kräuchi, N., 2005. Seasonal trends in reduced leaf gas exchange and ozone-induced foliar injury in three ozone sensitive woody plant species. Environ. Pollut. 136, 33-45.

Pääkkönen, E., Gunthardt-Goerg, M.S., Holopainen, T., 1998. Response of leaf processes in sensitive birch responses of leaf processes in a sensitive birch (Betula pendula Roth) clone to ozone combined with drought. Ann. Bot. 82, 49-59.

Paoletti, E., Contran, N., Manning, W.J., Castagna, A., Ranieri, A., Tagliaferro, F., 2008. Protection of ash (Fraxinus excelsior) trees from ozone injury by ethylenediurea (EDU): roles of biochemical changes and decreased stomatal conductance in enhancement of growth. Environ. Pollut. 155, 464-472.

Paoletti, E., Contran, N., Manning, W.J., Ferrara, A.M., 2009. Use of the antiozonant ethylenediurea (EDU) in Italy: verification of the effects of ambient ozone on crop 
plants and trees and investigation of EDU's mode of action. Environ. Pollut. 157, 1453-1460.

Pasqualini, S., Paoletti, E., Cruciani, G., Pellegrino, R., Ederli, L., 2016. Effects of different routes of application on ethylenediurea persistence in tobacco leaves. Environ. Pollut. 212, 559-564.

Pearson, M., Mansfield, T., 1994. Effects of exposure to ozone and water stress on the following season's growth of beech (Fagus sylvatica L.). New Phytol. 126, 511-515.

Piao, S.L., Ciais, P., Huang, Y., Shen, Z.H., Peng, S.S., Li, J.S., Zhou, L.P., Liu, H.Y., Ma, Y.C., Ding Y.H., Friedlingstein, P., Liu, C.Z., Tan, K., Yu, Y.Q., Zhang, T.Y., Fang, J.Y., 2010. The impacts of climate change on water resources and agriculture in China. Nature 467, 43-51.

Pollastrini, M., Desotgiu, R., Camin, F., Ziller, L., Gerosa, G., Marzuoli, R., Bussotti, F., 2014 Severe drought events increase the sensitivity to ozone on poplar clones. Environ. Exp. Bot. 100, 94-104.

Rai, R., Agrawal, M., Kumar Choudhary, K., Agrawal, S.B., Emberson, L., Büker, P., 2015. Application of ethylene diurea (EDU) in assessing the response of a tropical soybean cultivar to ambient $\mathrm{O}_{3}$ : nitrogen metabolism, antioxidants, reproductive development and yield. Ecotoxicol. Environ. Saf. 112, 29-38.

Reiner, S., Wiltshire, J.J.J., Wright, C.J., Colls, J.J., 1996. The impact of ozone and drought on the water relations of ash trees (Fraxinus excelsior L.). J. Plant Physiol. 148, 166-171.

Ryan, A., Cojocariu, C., Possell, M., Davies, W.J., Hewitt, C.N., 2009. Defining hybrid poplar (Populus deltoides $\times$ Populus trichocarpa) tolerance to ozone: identifying key parameters. Plant Cell Environ. 32, 31-45.

Sharkey, T., Bernacchi, C.J., Farquhar, G.D., Singsaas, E.L., 2007. Fitting photosynthetic carbon dioxide response curves for C3 leaves. Plant Cell Environ. 30, 1035-1040.

Singh, S., Agrawal, S.B., Agrawal, M., 2009. Differential protection of ethylenediurea (EDU) against ambient ozone for five cultivars of tropical wheat. Environ. Pollut. 157, 2359-2367.
The Royal Society, 2008. Ground-level ozone in the 21st century: future trends, impacts and policy implications. Science policy report 15/08. The Royal Society, London.

Tingey, D.T., Hogsett, W.E., 1985. Water stress reduces ozone injury via a stomatal mechanism. Plant Physiol. 77, 944-947.

Weidensaul, T.C., 1980. N-[2-(2-oxo-1-imidazolidinyl) ethyl]-N'-phenylurea as a protectant against ozone injury to laboratory fumigated pinto bean plants. Phytopathology 70 , 42-45.

Weisgerber, H., Han, Y.F., 2000. Diversity and breeding potential of poplar species in China. For. Chron. 77 (2), 227-237.

Wieser, G., Havranek, W.M., 1995. Environmental control of ozone uptake in Larix decidua Mill. : a comparison between different altitudes. Tree Physiol. 15, 253-258.

Wittig, V.E., Ainsworth, E.A., Naidu, S.L., Karnosky, D.F., Long, S.P., 2009. Quantifying the impact of current and future tropospheric ozone on tree biomass, growth, physiology and biochemistry: a quantitative meta-analysis. Glob. Chang. Biol. 15, 396-424.

Yamaji, K., Ohara, T., Uno, I., Kurokawa, J.-I., Pochanart, P., Akimoto, H., 2008. Future prediction of surface ozone over East Asia using models-3 community multiscale air quality modeling system and regional emission inventory in Asia. J. Geophys. Res. 113.

Yuan, X., Calatayud, V., Jiang, L., Manning, W.J., Hayes, F., Tian, Y., Feng, Z., 2015. Assessing the effects of ambient ozone in China on snap bean genotypes by using ethylenediurea (EDU). Environ. Pollut. 205, 199-208.

Zhou, J, Zhang Z.Q, Sun, G, Fang X.R, Zha, T.G, McNulty, S, Chen, J.Q., Jin, Y. Noormmets, A., 2013. Response of ecosystem carbon fluxes to drought events in a poplar plantation in Northern China. For. Ecol. Manag. 300, 33-42.

Zhou, L., Wang, S.Q., Chi, Y.G., Li, Q.K., Huang, K., Yu, Q.Z., 2015. Responses of photosynthetic parameters to drought in subtropical forest ecosystem of China. Sci. Rep. 5 , 18254. 